\title{
AVALIAÇÃO AGRONÔMICA DE HÍBRIDOS DE SORGO GRANÍFERO CULTIVADOS SOB IRRIGAÇÃO E ESTRESSE HÍDRICO
}

\author{
FLÁVIO DESSAUNE TARDIN ${ }^{1}$, JANEO EUSTÁQUIO DE ALMEIDA FILHO², CINTIA MACHADO DE \\ OLIVEIRA $^{2}$, CARLOS EDUARDO DO PRADO LEITE ${ }^{1}$, CÍCERO BESERRA DE MENEZES ${ }^{1}$, PAULO \\ CÉSAR MAGALHÃES ${ }^{1}$, JOSÉ AVELINO SANTOS RODRIGUES ${ }^{1}$ e ROBERT EUGENE SCHAFFERT ${ }^{1}$
}

'Embrapa Milho e Sorgo, Sete Lagoas, MG, Brasil,flavio.tardin@embrapa.br, carlos.prado@embrapa.br, cicero.menezes@embrapa.br, paulo.magalhaes@embrapa.br,avelino.rodrigues@embrapa.br,robert.schaffer@embrapa.br

2Uenf, Campos dos Goytacazes, RJ,Brasil,janeoeaf@uenf.com.br, ciintiia@yahoo.com.br

$\overline{\text { Revista Brasileira de Milho e Sorgo, v.12, n.2, p. 102-117, } 2013}$

\begin{abstract}
RESUMO - Diante da importância de cultivo da cultura do sorgo em ambientes passíveis de estresse hídrico, objetivou-se neste trabalho a avaliação de 49 híbridos simples de sorgo granífero em dois ambientes contrastantes, um deles com irrigação plena e outro com estresse hídrico induzido após o florescimento das plantas. Em geral, não foi observado efeito da interação genótipo por ambiente para a maioria das características e o estresse hídrico proporcionou decréscimo nas médias das variáveis avaliadas: rendimento de grãos, altura, florescimento e índice de trilha, que é a relação, em porcentagem, da massa de grãos em relação à massa total da panícula. A alta produtividade de grãos no ambiente com estresse hídrico está associada, possivelmente, ao rápido desenvolvimento das plantas, enquanto no ambiente irrigado está associada ao maior período vegetativo e, em todos os casos, indivíduos com alto índice de trilha tendem a ser mais produtivos. A altura não foi fator limitante para a grande maioria dos híbridos de sorgo avaliados. Diversos híbridos experimentais foram mais precoces do que as cultivares comerciais utilizadas como testemunhas, em ambos os ambientes. Os híbridos 0306037 e 0009035 se destacaram por apresentar altas produtividades de grãos e serem precoces. As cultivares DKB 599 e 1 G150 também apresentaram alta produtividade de grãos.
\end{abstract}

Palavras-chave: Sorghum bicolor; estresse abiótico; produtividade de grãos.

\section{AGRONOMIC ANALYSIS OF GRAIN SORGHUM HYBRIDS GROWN UNDER IRRIGATION AND WATER STRESS}

\begin{abstract}
Due to the importance of the cultivation of sorghum in environments subject to water stress, this study aimed to evaluate 49 simple hybrids of grain sorghum in two contrasting environments, one with irrigation during all time of plants development and other with induced water stress after plant flowering. In general, no effect of the interaction between genotype and environment was observed for the most traits, and water stress caused a decrease in the values of the variables: grain yield, height, flowering, and threshing index (the ratio between grain weight and panicle weight). Possibly, the high grain yield observed in the environment subjected to water stress, is associated with the fast development of plants, whereas in the irrigated environment is associated with a good vegetative growth. In all the cases, genotypes with high threshing index tend to be more productive. The height was not a limiting factor for most of the hybrids. Several hybrids showed early cycles than commercial cultivars in both environments. The hybrids 0306037 and 0009035 were superior, presenting high grain yield and precocity. The cultivars DKB 599 and 1 G150 also presented high grain yield.
\end{abstract}

Key words: Sorghum bicolor; abiotic stress; yield. 
A agricultura brasileira possui vantagem de interesse ao agronegócio, em razão da possibilidade de cultivo de duas safras num mesmo ano agrícola, sendo que o segundo cultivo é conhecido como cultivo de segunda safra ou safrinha. O ambiente na época da safrinha é, sabidamente, marcado por insuficiência hídrica para muitas culturas. Nesse contexto, é imprescindível a utilização de espécies mais adaptadas a essas condições climáticas.

A utilização do sorgo no cultivo de safrinha é uma importante alternativa, pois é uma espécie tolerante ao estresse hídrico e, de acordo com Stone et al. (1996), é mais eficiente para produção de grãos do que o milho, cultura comumente utilizada no Brasil em plantios de segunda safra.

Singh et al. (1995) observaram que o sorgo apresentou melhor desempenho que o milho em todas condições de estresse hídrico induzido para produção de matéria seca e que as raízes do sorgo exploravam muito mais o solo para absorção de água. Segundo Magalhães et al. (2003), a massa de raiz seminal do milho e do sorgo são similares, entretanto a massa das raízes secundárias do sorgo é, no mínimo, o dobro da massa das raízes secundárias do milho.

Segundo Blum \& Sullivan (1986), o sorgo faz maior ajuste osmótico, se comparado com milho e milheto, sendo mais tolerante à seca que as outras espécies.

O sorgo é dotado de mecanismos morfológicos e bioquímicos que conferem características xerófitas. Essa espécie possui uma cerosidade natural que o leva a perder menos água durante a transpiração. Em condições de estresse hídrico, a planta possui mecanismos de defesa que, nessas condições, diminuem o seu metabolismo e enrolam suas folhas e, finalizado o período de estresse hídrico, o estado normal de desenvolvimento retorna de forma extraordinária (Magalhães \& Durães, 2003). De acordo com os mesmos autores, o sorgo também apresenta maior eficiência na utilização da água que outros cereais, uma vez que ele necessita de 3301 de água para produzir $1 \mathrm{~kg}$ de matéria seca, enquanto o milho e o trigo necessitam de aproximadamente 370 e 5001 , respectivamente.

$\mathrm{O}$ estresse hídrico tem influência em todas as fases na cultura do sorgo, desde a germinação, quando é possível discriminar sementes com melhor qualidade fisiológica (Torres, 1997; Oliveira \& Gomes Fiho, 2009), até nas fases finais do enchimento de grãos. Todavia, a fase onde o estresse hídrico proporciona maior perda de produtividade de grãos é na fase reprodutiva (Lima et al., 2011). Com o estresse nessa fase, várias sementes em potencial deixam de ser formadas, seja pelo abortamento ou pelo desenvolvimento insuficiente da panícula, e, mesmo após a fertilização do óvulo, o estresse hídrico compromete o enchimento de grãos.

Ressalva-se que, no Brasil, o sorgo granífero é cultivado em sua quase totalidade no período da segunda safra e em condições de sequeiro (Associação.., 2012), aproveitando o final da época chuvosa, sendo assim mais frequente a ocorrência de veranicos após o florescimento das lavouras. Assim, torna-se imprescindível a disponibilidade de cultivares comerciais de sorgo tolerantes ao estresse hídrico, principalmente no período de pós-florescimento.

Ao realizar o melhoramento de uma cultura de segunda safra, deve-se considerar a instabilidade de precipitação pluviométrica. Desta 
forma, não basta apenas obter uma cultivar adaptada às condições de estresse hídrico, mas também que esta seja responsiva ao incremento do suprimento hídrico que porventura possa ocorrer em condições ambientais favoráveis.

Diante do exposto, objetivou-se, neste trabalho, avaliar agronomicamente o desempenho de híbridos de sorgo em condições de irrigação plena e em estresse hídrico em pós-florescimento.

\section{Material e Métodos}

Quarenta e nove híbridos de sorgo granífero, sendo 45 oriundos do Programa de Melhoramento Genético da Embrapa Milho e Sorgo e quatro comerciais ( $1 \mathrm{G}$ 150, BRS 309, BRS 310 e DKB 599) recomendados para cultivo na região Sudeste do Brasil, foram avaliados em dois ambientes. No primeiro ambiente, os genótipos foram submetidos a uma condição de cultivo irrigado durante todo o ciclo das plantas, sendo que, no segundo ambiente, cessou-se a irrigação após o início da fase reprodutiva, objetivando submeter os híbridos ao estresse hídrico.

Ambos os experimentos foram implantados em julho de 2008 na Fazenda Experimental do Gorutuba, pertencente à Embrapa Milho e Sorgo e localizada no município de Nova Porteirinha, $\mathrm{MG}$, coordenadas geográficas $43,3^{\circ} \mathrm{O}$ e $15,8^{\circ} \mathrm{S}$, em latossolo vermelho-amarelo de textura média. O local e a época de implantação dos experimentos foram escolhidos pelo histórico de ocorrência de baixa incidência de precipitação pluviométrica, de forma que o suprimento de água fosse controlado apenas por irrigação, sem interferências de chuvas, durante a condução dos ensaios. Os dados climáticos do período em que se conduziu o experimento podem ser observados na Figura 1.

Estes experimentos foram implantados sob o delineamento látice triplo 7 × 7 , ou seja, cada

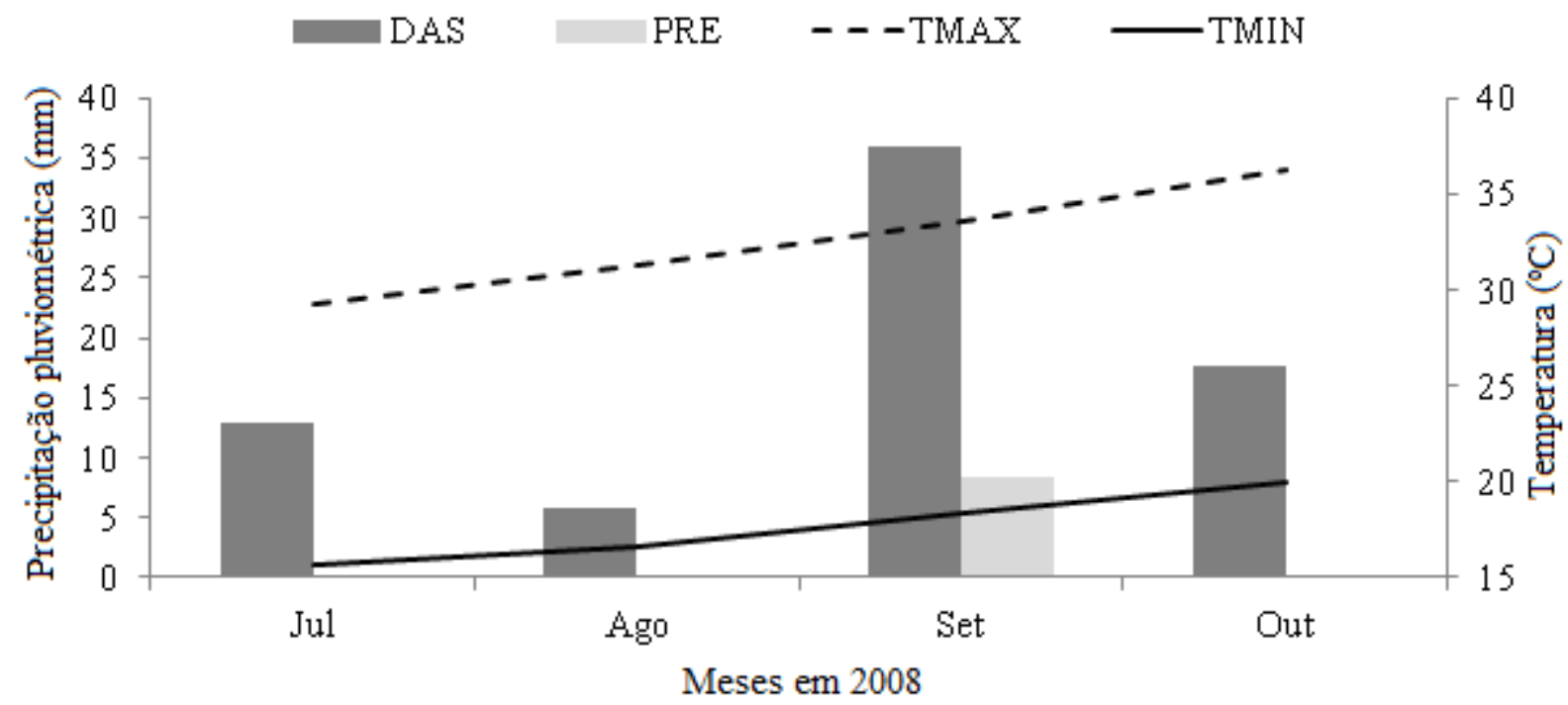

FIGURA 1. Dados da quantidade de água armazenada em solos sem irrigação (DAS), de precipitação pluviométrica (PRE) em mm, de temperatura média máxima e mínima (TMAX e TMIN) em $\left({ }^{\circ} \mathrm{C}\right)$, durante o período de condução do experimento. Fazenda Experimental do Gorutuba, Nova Porteirinha, MG, 2008 (Agritempo, 2010). 
tratamento foi repetido três vezes, sendo as unidades experimentais compostas por duas linhas de cinco metros, espaçadas em $0,5 \mathrm{~m}$. A semeadura na linha foi realizada com excesso de sementes para que, após o desbaste de plantas ocorrido aos 30 dias após a semeadura, se deixasse na parcela um estande de 200.000 plantas $\mathrm{ha}^{-1}$. A bordadura entre as linhas foi realizada com as parcelas adjacentes. Para as parcelas que não possuíam parcelas adjacentes, foi semeada uma linha com densidade de semeadura igual à do experimento, servindo de bordadura. A bordadura dentro da linha foi realizada com extremidades de 0,5 m de cada linha; com isso, a área útil de cada parcela foi de duas linhas de quatro metros.

A irrigação do experimento foi realizada por aspersão convencional, sendo que, em um ambiente, a irrigação foi realizada até a maturação fisiológica dos grãos e, no outro, a irrigação foi cortada 45 dias após a semeadura, para que a água disponível no solo, a partir desta data, reduzisse e os genótipos fossem submetidos a estresse hídrico no início do seu florescimento.

Para o controle de pragas de solo, foi utilizado o produto Furadan 100 GR no sulco de plantio, antes da semeadura, na dosagem de $20 \mathrm{~kg} \mathrm{ha}^{-1}$. O manejo de lagartas foi realizado com inseticidas de contato, de acordo com a recomendação do fabricante.

Como medida de impedir o ataque de pássaros nos grãos, as panículas foram cobertas com sacolas de polietileno. A adubação de plantio utilizou $250 \mathrm{~kg} \mathrm{ha}^{-1}$ da formulação N-P-K 8-28-16 e $100 \mathrm{~kg} \mathrm{ha}^{-1}$ de ureia aplicados em cobertura aos 30 dias após o plantio.

As características avaliadas foram: a) altura de plantas em $\mathrm{cm}$, medindo o comprimento entre o colo da planta e o ápice da panícula no momento da maturação fisiológica; b) florescimento, computando os dias entre a semeadura e o florescimento, considerando o florescimento na parcela quando, em mais de $50 \%$ das plantas, as flores do terço médio da panícula entraram em antese; c) rendimento de grãos, obtido pela medição da massa e da umidade dos grãos da parcela e corrigindo-se o valor da massa para umidade de $13 \%$, seguindo a fórmula:

$$
\mathrm{Mc}=\operatorname{Mo}(100-\mathrm{Uo}) 87^{-1} \text {, }
$$

sendo Mc e Mo massa corrigida e observada, respectivamente; Uo: umidade observada; d) índice de trilha, que é a relação em \% da massa de grãos em relação à massa total da panícula.

A análise estatística dos dados se procedeu inicialmente com a análise de variância, sendo analisada a viabilidade de se utilizar a avaliação dos ambientes conjuntamente, seguindo o delineamento em látice, considerando a proposta de Regazzi et al. (1999), utilizando a recuperação da informação interblocos. A viabilidade dessa análise foi mensurada pela eficiência em relação à avaliação, considerando o delineamento em blocos ao acaso (DBC), conforme descrito em PimentelGomes (2009). Para as características que o uso do látice foi menos eficiente que o DBC, foi considerada a análise no delineamento de blocos ao acaso. As análises de variância foram realizadas pelo software Genes (Cruz, 2006).

Após a realização das análises de variâncias, foram calculados os valores das diferenças mínimas significativas (DMS), seguindo o teste de Tukey a 5\% de probabilidade, para a avaliação de todos os contrastes entre duas médias dentro do mesmo ambiente, sendo utilizadas as médias ajustadas para as características em que a avaliação, considerando o látice, foi mais eficiente, conforme Pimentel-Gomes (2009). 
Também foi ajustado um modelo de regressão linear múltipla, considerando o rendimento de grãos como variável dependente e as outras características avaliadas como variáveis explicativas. Para o ajuste do melhor modelo, foi considerado o procedimento Stepwise, sendo esse descrito em Schuster \& Cruz (2008). Essas análises foram realizadas com o software SAS, versão 9.2 (SAS, 2008).

\section{Resultados e Discussão}

A análise de variância, considerando-se o esquema látice com recuperação da informação interblocos, foi mais eficiente que a análise considerando o delineamento de blocos completos ao acaso para as variáveis: altura, florescimento e rendimento de grãos. Com isso, foi considerada essa análise para essas características e as médias analisadas foram as médias ajustadas (Least Square Means), conforme preconizam Pimentel-Gomes (2009). Enquanto que, para a variável índice de trilha, a análise seguindo o látice não foi eficiente; por isso, não foi utilizada (Tabela 1).

As características altura de plantas, florescimento e índice de trilha apresentaram baixos coeficientes de variação, de acordo com PimentelGomes (2009). Para a produtividade de grãos, o coeficiente foi de maior magnitude; contudo, esse resultado era esperado em virtude dessa característica ser bastante influenciada pelo ambiente.

Esses resultados foram concordantes com Silva et al. (2009), enquanto que Mariguele \& Silva (2002) reportaram maior coeficiente de variação para o índice de trilha, sendo que, em ambos os trabalhos, os coeficientes de variação

TABELA 1. Resumo das análises de variâncias conjuntas. Nova Porteirinha, MG, 2008.

\begin{tabular}{|c|c|c|c|c|c|c|c|c|}
\hline \multirow[t]{2}{*}{ FV } & \multicolumn{2}{|c|}{$\begin{array}{c}\text { Altura } \\
(\mathrm{cm})\end{array}$} & \multicolumn{2}{|c|}{$\begin{array}{l}\text { Florescimento } \\
\text { (dias) }\end{array}$} & \multicolumn{2}{|c|}{$\begin{array}{l}\text { Índice de trilha } \\
(\%)\end{array}$} & \multicolumn{2}{|c|}{$\begin{array}{c}\text { Produtividade de grãos } \\
\qquad\left(\mathrm{kg} \mathrm{ha}^{-1}\right)\end{array}$} \\
\hline & QM & $\mathrm{P}(>\mathrm{F})$ & QM & $\mathrm{P}(>\mathrm{F})$ & QM & $\mathrm{P}(>\mathrm{F})$ & QM & $\mathrm{P}(>\mathrm{F})$ \\
\hline Gen & 765,41 & $<0,01$ & 28,43 & $<0,01$ & 25,11 & 0,13 & 3977649,74 & $<0,01$ \\
\hline $\mathrm{Amb}$ & 54557,91 & $<0,01$ & 180,72 & $<0,01$ & 2737,47 & $<0,01$ & 1086787046,23 & $<0,01$ \\
\hline Gen x Amb & 57,05 & $\mathrm{~F} \leq 1$ & 1,05 & 0,07 & 18,39 & $\mathrm{~F} \leq 1$ & 1233976,23 & $\mathrm{~F} \leq 1$ \\
\hline Erro $^{1}$ & 75,75 & & 0,76 & & 19,75 & & 1370717,01 & \\
\hline $\mathrm{CV}(\%)$ & 8,05 & & 1,24 & & 5,85 & & 22,66 & \\
\hline Média C.E. ${ }^{2}$ & 94,46 & & 69,25 & & 72,95 & & 3243,25 & \\
\hline Média S.E. & 121,70 & & 70,82 & & 79,05 & & 7088,53 & \\
\hline $\operatorname{Ef}(\%)$ & 134,53 & & 116,34 & & - & & 115,76 & \\
\hline
\end{tabular}

$\mathrm{P}(>\mathrm{F})$ : Valor $\mathrm{p}$ do teste $\mathrm{F}$, quando $\mathrm{F}>1 .{ }^{1} \mathrm{O}$ erro das variáveis altura, florescimento e rendimento de grãos é o erro efetivo médio associado a 156 graus de liberdade, enquanto que o erro da variável IC é o erro obtido pela análise em DBC associado a 194 graus de liberdade. Ef(\%) é a eficiencia relativa do uso da análise em Lattice em relação a análise de DBC; ${ }^{2}$ Média C.E. e Média S.E. referem-se às médias dos ambientes com e sem estresse, respectivamente. 


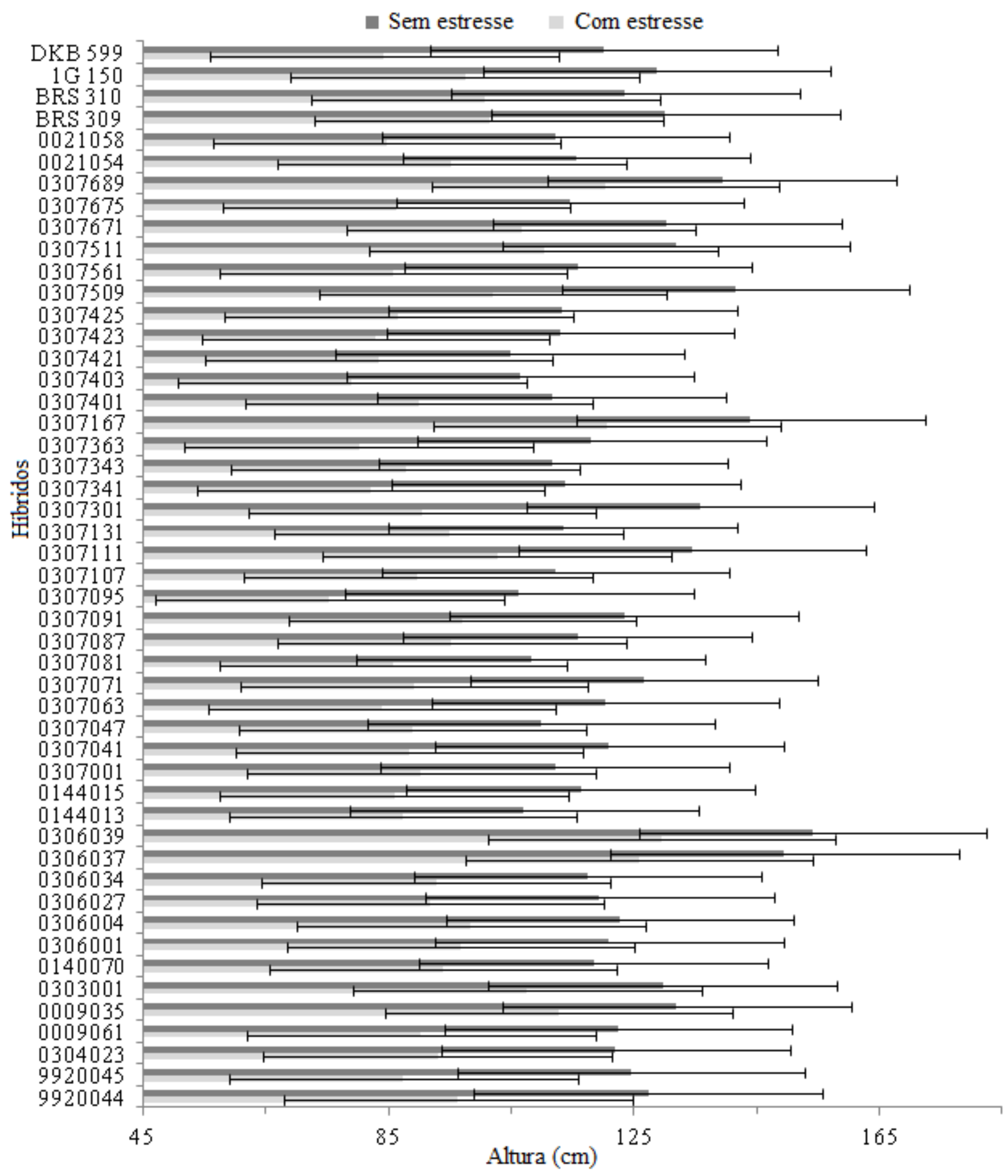

FIGURA 2. Médias de altura dos híbridos nos ambientes com e sem estresse. Barra de intervalos equivale a duas vezes a diferença mínima significativa (DMS) do teste de Tukey a 5\%. Fazenda Experimental do Gorutuba, Nova Porteirinha, MG, 2008. 


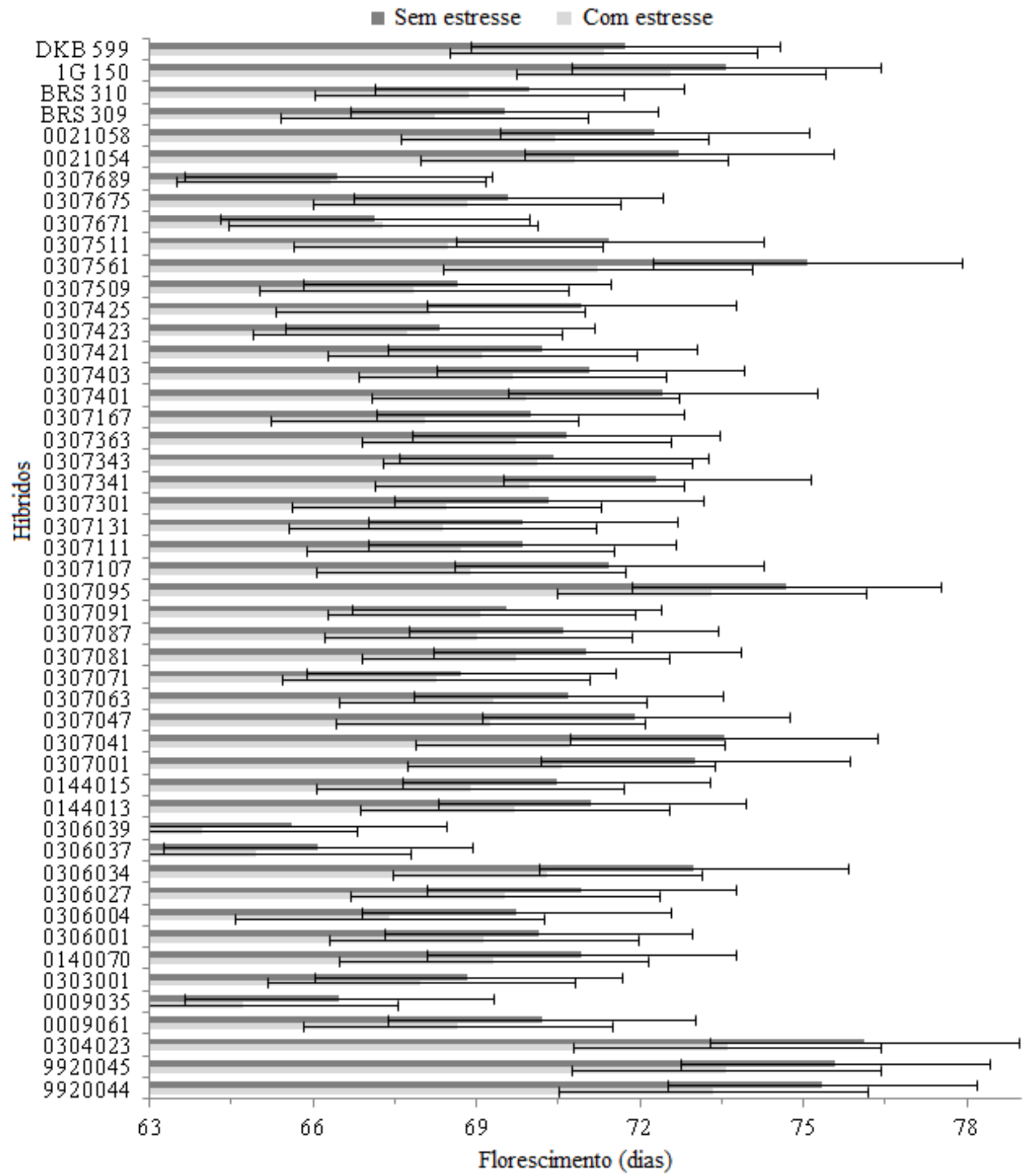

FIGURA 3. Médias do número de dias entre o florescimento e a semeadura dos híbridos nos ambientes com e sem estresse. Barra de intervalos equivale a duas vezes a diferença mínima significativa (DMS) do teste de Tukey a 5\%. Fazenda Experimental do Gorutuba, Nova Porteirinha, MG, 2008. 


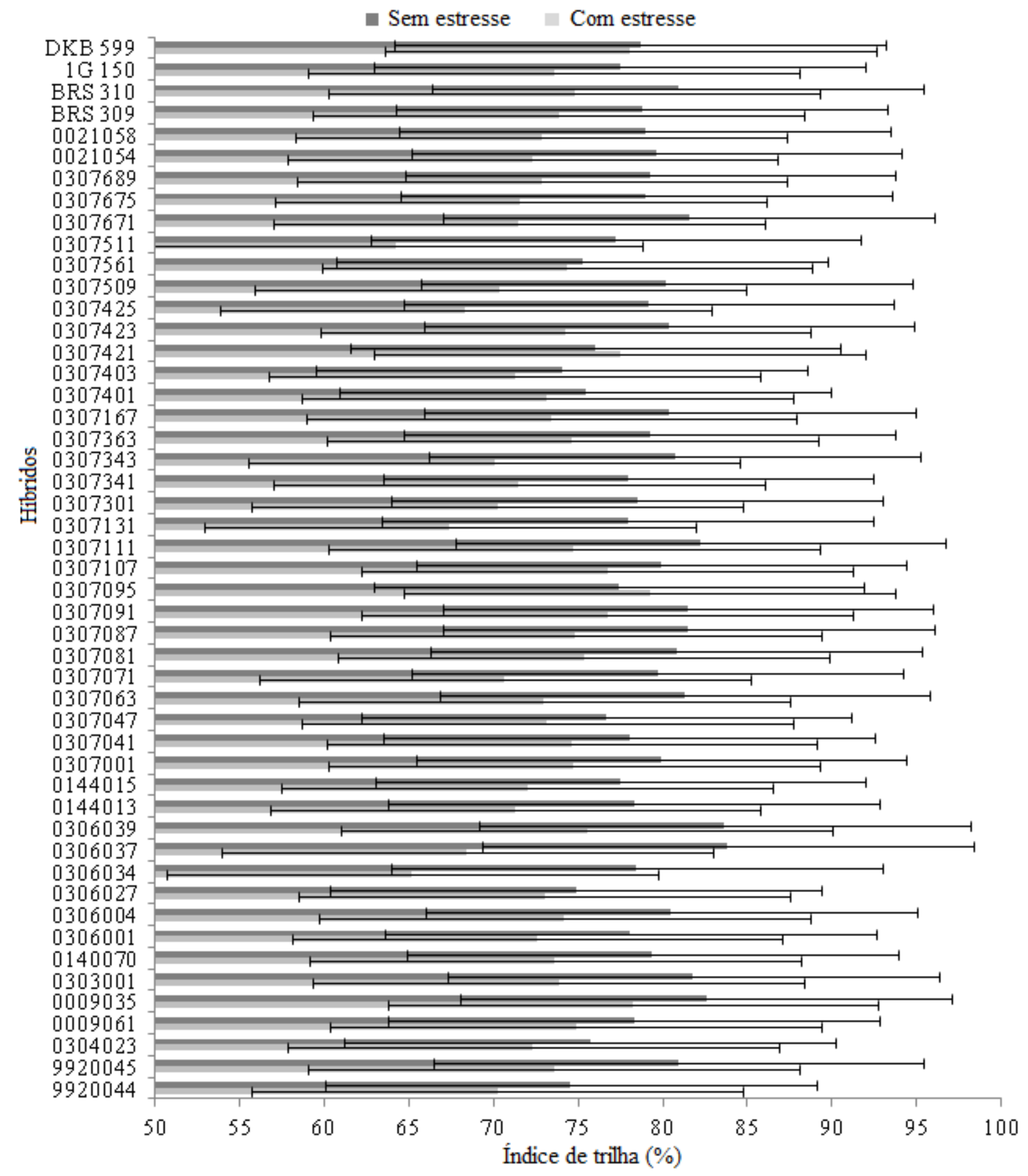

FIGURA 4. Médias do índice de trilha dos híbridos nos ambientes com e sem estresse. Barra de intervalos equivale a duas vezes a diferença mínima significativa (DMS) do teste de Tukey a 5\%. Fazenda Experimental do Gorutuba, Nova Porteirinha, MG, 2008.

Revista Brasileira de Milho e Sorgo, v.12, n.2, p. 102-117, 2013

Versão impressa ISSN 1676-689X / Versão on line ISSN 1980-6477 - http://www.abms.org.br 


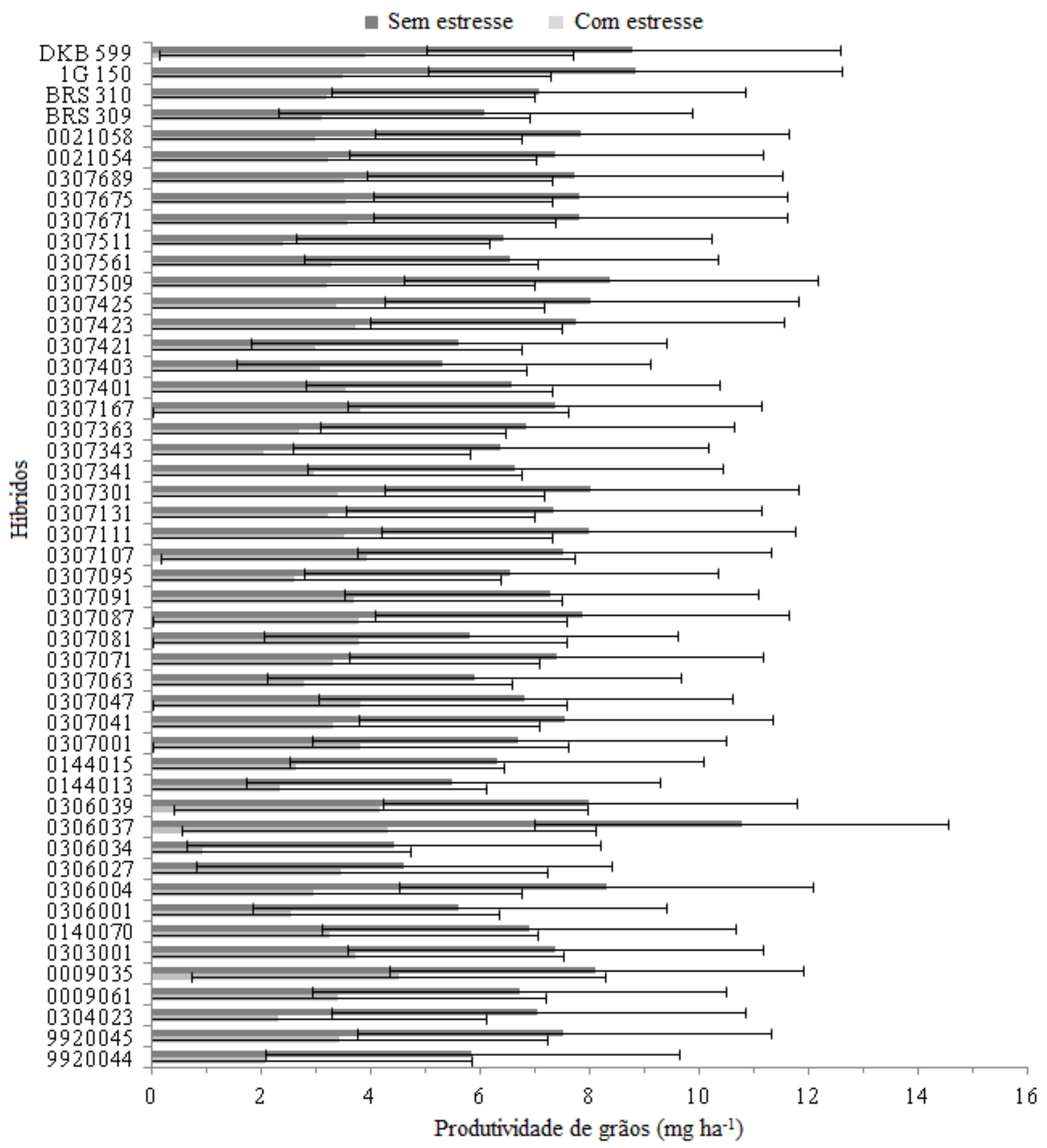

FIGURA 5. Médias da produtividade média dos híbridos nos ambientes com e sem estresse. Barra de intervalos equivale a duas vezes a diferença mínima significativa (DMS) do teste de Tukey a 5\%. Fazenda Experimental do Gorutuba, Nova Porteirinha, MG, 2008. 
para produtividade de grãos foram menores que os observados nesta pesquisa.

Pelos resultados da análise de variância, foi observado que não ocorreu interação genótipo $\mathrm{x}$ ambiente ( $\mathrm{G} \times \mathrm{A}$ ) para quase todas as características avaliadas, exceto para florescimento, a qual demonstrou significância ao nível de $7 \%$ de probabilidade pelo teste F. Esses resultados indicam que os indivíduos de maior mérito agronômico em um ambiente tendem a se destacar no outro ambiente também.

Houve diferenças significativas entre os dois ambientes para todas as características avaliadas, sendo observadas médias inferiores no ambiente com estresse hídrico (Figuras 2, 3, 4, 5).

Este resultado não era esperado para a característica florescimento, uma vez que o intuito inicial da pesquisa era que o corte da irrigação aos 45 dias após a semeadura acarretasse estresse hídrico após o florescimento das plantas, ou seja, os dois ambientes avaliados seriam tratados da mesma forma até o florescimento. Entretanto, observa-se, na Tabela 1, que o florescimento das plantas no ambiente com estresse ocorreu primeiro que no ambiente irrigado.

Apesar da pequena diferença, em termos de valor absoluto, entre as médias de florescimento dos dois ambientes, menos de dois dias, a mesma foi suficiente para significância do teste $F$ $(\mathrm{p}<0,01)$. Este resultado, associado aos valores observados na Figura 3, referente às médias para florescimento dos híbridos, demonstram que o corte de irrigação, aos 45 dias após o plantio, promoveu estresse hídrico antes do início de florescimento de todos os híbridos e não após o florescimento, como se preconizava.

Ainda, a existência de diferenças entre médias de florescimentos entre os híbridos contribui para a ocorrência da interação $\mathrm{G}$ x A, conforme foi observada. Possivelmente, genótipos mais precoces, devido à falta de água ter ocorrido bem próximo da época de florescimento natural do mesmo, não tiveram seu florescimento antecipado pelo estresse hídrico, enquanto que, nos materiais mais tardios, podem ter sido ativados mecanismos fisiológicos para sobrevivência dos mesmos no ambiente com restrição hídrica, acelerando seu florescimento e os aproximando dos demais materiais, uma vez que, segundo Turner (1986), um mecanismo natural das plantas completarem seu ciclo sob estresse hídrico é o rápido desenvolvimento.

O estresse hídrico desencadeia uma série de mudanças fisiológicas, como o fechamento de estômatos, reduzindo a entrada de $\mathrm{CO}_{2}$ no mesófilo, diminuindo a matériaprima para o processo fotossintético, o que compromete o desenvolvimento da planta. De acordo com Turner (1986), fatores que adiam a desidratação por reduzir a perda de água, como a redução na condutância estomática e no crescimento foliar, são processos que reduzem também a produtividade.

O efeito de híbridos foi não significativo a 5\% para a variável índice de trilha, enquanto que, para as outras variáveis, o efeito de híbridos foi significativo e pronunciado $(\mathrm{p}<0,01)$ (Tabela 1$)$, o que indica existir um potencial genético a ser explorado para essas características.

Diferente dos resultados desse trabalho, Albuquerque et al. (2011) observaram interação G $\mathrm{x}$ A entre as cultivares de sorgo granífero por eles avaliadas diante da variação de um ano chuvoso e um ano seco.

Ao avaliarem cultivares de sorgo granífero sob estresse abiótico, Fernandes et al. (1992) também observaram efeitos da interação entre genótipo com ambientes. Porém, nesse caso, o estresse era causado 
por solos salinizados. Silva et al. (2009) observaram efeito significativo da interação genótipo e ambiente em diferentes ambientes tradicionais de cultivo.

Resultados contrastantes deste trabalho com os encontrados na literatura, quanto à interação G x A, levam a crer que existem outros mecanismos associados a uma resposta diferenciada para as características: produção de grãos, altura e índice de trilha, sob estresse hídrico, que se manifestam em outros estádios da cultura do sorgo ou que, por muitos dos híbridos experimentais avaliados já terem passado por diversos ciclos de seleção e serem provenientes de linhagens aparentadas, apresentam, por consequência, algumas características fisiológicas semelhantes, respondendo semelhantemente à variação ambiental.

Para a altura de cultivares de sorgo granífero, Santos (2003) recomenda que a mesma esteja no intervalo de 1,0 a $1,5 \mathrm{~m}$, aproximadamente, pois a colheita dessa cultura geralmente é realizada com adaptações de colhedoras para milho ou soja, as quais operam neste intervalo. Associadas a isto, alturas inferiores a 1,5 m são desejadas para se evitarem problemas de acamamento das plantas, característica esta correlacionada positivamente à altura das plantas. Altura superior a 1,0 m é recomendada, pois esta característica está positivamente correlacionada com produtividade de grãos.

No ambiente sem estresse hídrico, a altura não foi fator limitante (Figura 2), uma vez que as médias variaram de 105 a $154 \mathrm{~cm}$. Já no ambiente com estresse hídrico, as alturas variaram de 75 a $130 \mathrm{~cm}$; porém, nenhuma média foi estatisticamente inferior a $1,0 \mathrm{~m}$ e nem superior a 1,5 m. Silva et al. (2009) observaram alturas de cultivares de sorgo variando entre 1,0 e 1,2 m; Heckler (2002) observou valores entre 0,95 e 1,66 m; e Mariguele \& Silva (2002) observaram médias entre 1,35 e 1,73 m.

Para florescimento, foi observado que vários híbridos experimentais foram estatisticamente mais precoces, tanto em relação aos híbridos comerciais, quanto em relação à média ambiental nos dois ambientes, com destaque para os híbridos 0306039, 0306037, 0307689 e 0009035, por terem sido precoces nos dois ambientes (Figura 3 ).

A precocidade é uma característica interessante para cultivares de sorgo granífero, pois, como o cultivo dessa cultura é realizado quase que totalmente na safrinha (Associação.., 2012), é importante que a cultura permaneça o menor tempo possível em condições adversas. Outro ponto favorável à utilização de cultivares precoces é que a colheita antecipada do sorgo granífero permite que os agricultores tenham maior flexibilidade na negociação dos grãos e, consequentemente, obtenham maior rentabilidade com sua produção (Silva et al., 2009). Esses autores também ressaltam que é interessante que o agricultor tenha à disposição cultivares com diferentes períodos de florescimento, pois permite que o produtor escalone a colheita, adequando o uso do maquinário agrícola.

Outro ponto que também deve ser considerado é o de se tentar realizar semeadura mais cedo com cultivares mais tardias, devido ao seu maior potencial produtivo de grãos em função da possibilidade de maior acúmulo de matéria seca.

Nesse contexto, vale ressaltar que vários híbridos estudados estão em uma faixa aceitável de dias para o florescimento, podendo-se indicar cultivares para diferentes épocas de plantio, uma vez que a variação entre a mais precoce e a mais tardia foi de aproximadamente 10 dias nos dois ambientes. 
Os híbridos avaliados se mostraram mais precoces que as cultivares avaliadas por Silva et al. (2009), porém, dentro do intervalo de médias para florescimento observado por Heckler (2002), com valores entre 62 e 79 dias após a semeadura.

Para produtividade de grãos, observou-se que os híbridos 030637, 1G150 e DKB 599 apresentaram maior destaque, com produtividade de 10.781; 8.839 e $8.801 \mathrm{~kg} \mathrm{ha}^{-1}$, respectivamente, no ambiente sem estresse hídrico (Figura 5). No ambiente com estresse hídrico, tais materiais também apresentaram produtividades de grãos acima da média, sendo os híbridos 0306037 e DKB 599 o segundo e o quinto mais produtivos, com médias de 4.327 e $3.912 \mathrm{~kg} \mathrm{ha}^{-1}$, respectivamente. A maior média observada nesse ambiente foi de $4.509 \mathrm{~kg} \mathrm{ha}^{-1}$, com o híbrido 0009035. Entretanto, nenhum contraste entre duas médias foi estatisticamente diferente de zero nesse ambiente $(\mathrm{p}<0,05)$.

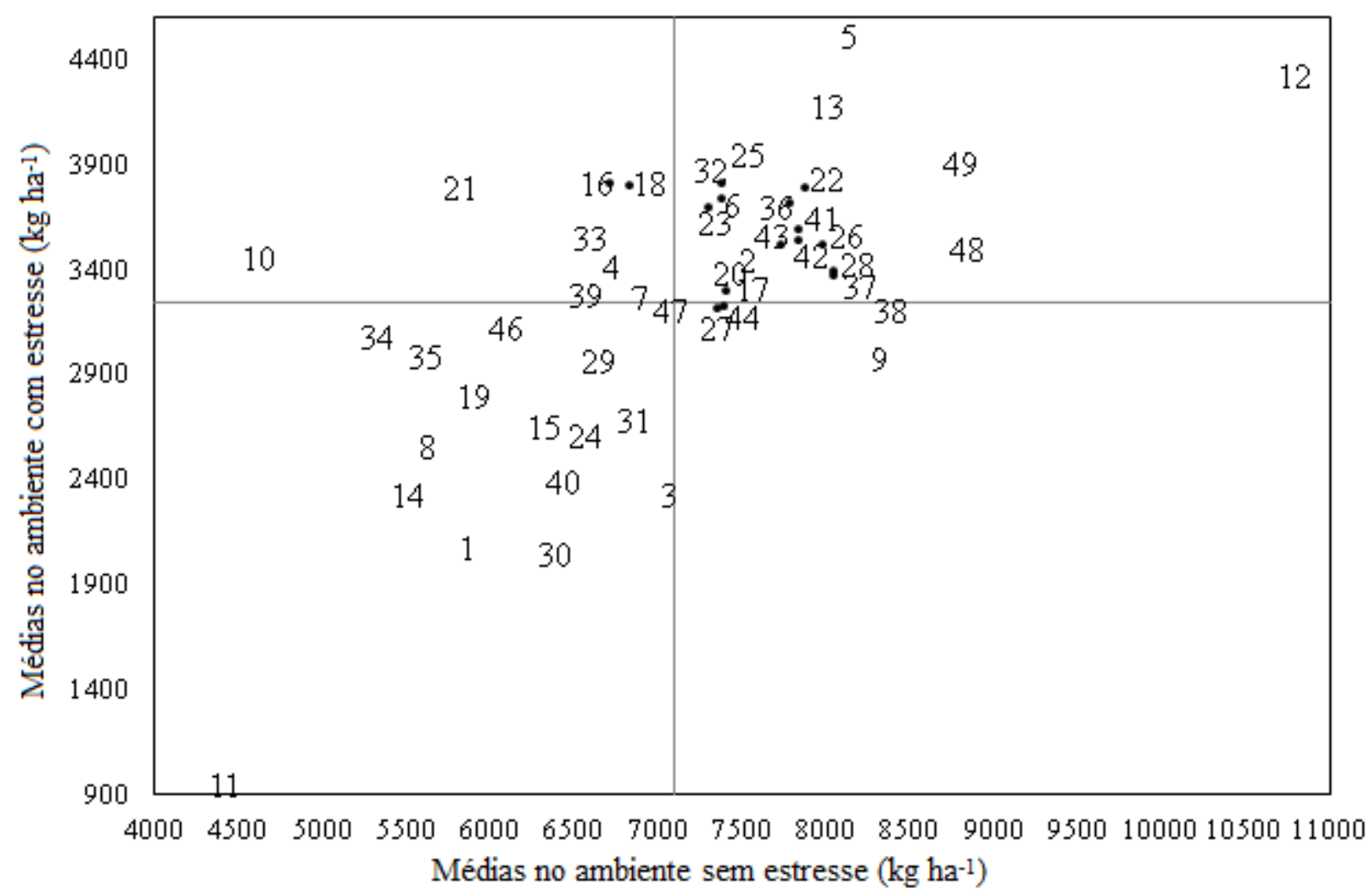

FIGURA 6. Médias da produtividade de grãos dos híbridos de sorgo: 9920044 (1); 9920045 (2);0304023 (3); 0009061 (4); 0009035 (5); 0303001 (6); 0140070 (7); 0306001 (8); 0306004 (9); 0306027 (10); 0306034 (11); 0306037 (12); 0306039 (13); 0144013 (14); 0144015 (15); 0307001 (16); 0307041 (17); 0307047 (18); 0307063 (19); 0307071 (20); 0307081 (21); 0307087 (22); 0307091 (23); 0307095 (24); 0307107 (25); 0307111 (26); 0307131 (27); 0307301 (28); 0307341 (29); 0307343 (30); 0307363 (31); 0307167 (32); 0307401 (33); 0307403 (34); 0307421 (35); 0307423 (36); 0307425 (37); 0307509 (38); 0307561 (39); 0307511 (40); 0307671 (41); 0307675 (42); 0307689 (43); 0021054 (44); 0021058 (45); BRS 309 (46); BRS 310 (47); 1G 150 (48) e DKB 599 (49) nos dois ambientes avaliados. Fazenda Experimental do Gorutuba, Nova Porteirinha, MG, 2008. 
Pela análise descritiva dos dados de produtividade de grãos e pela comparação em termos de valores absolutos das médias obtidas pelos híbridos em relação à média geral observada em cada ambiente, os híbridos podem ser classificados em quatro grupos distintos, de acordo com os quadrantes da Figura 6. No primeiro quadrante, estão representados os híbridos de desempenhos abaixo da média nos dois ambientes. O segundo quadrante é composto por híbridos que não toleraram bem o estresse hídrico, mas são responsivos ao suprimento hídrico. Já no terceiro quadrante, se encontram os híbridos de maior mérito, pois tanto foram tolerantes ao estresse hídrico, como também responderam acima da média ao suprimento hídrico, com destaque para os genótipos 0009035 e 030637 , que foram os que mais produziram nos dois ambientes avaliados. No quarto quadrante, estão os híbridos tolerantes ao estresse induzido, porém, que não apresentaram uma resposta consistente às condições favoráveis, uma vez que demonstraram valores acima da média para o ambiente sob estresse e abaixo da média para o irrigado.

Ratificando, o resultado da interação genótipo $\mathrm{x}$ ambiente não significativa (Tabela 1) observou-se que a maioria dos híbridos está classificada como tolerantes e responsivos ou não tolerantes e não responsivos. Esses resultados indicam que, se um híbrido é tolerante ao estresse hídrico na fase de pré-florescimento, é esperado que ele também tenha um bom desempenho nas condições hídricas favoráveis.

Com relação às cultivares comerciais, os híbridos 1G150 e DKB 599 se destacaram por apresentarem tolerância ao estresse hídrico e responderem bem ao suprimento de água, com médias superiores em ambos os ambientes. O híbrido BRS 310 se mostrou tolerante ao estresse hídrico, porém de comportamento pouco responsivo à melhoria ambiental. O híbrido BRS 309 não apresentou bom desempenho, com médias abaixo da média ambiental nos dois ambientes.

A grande maioria dos híbridos apresentaram produtividade de grãos superior à média brasileira, que se apresenta em torno de $2.400 \mathrm{~kg} \mathrm{ha}^{-1}$ (IBGE, 2011) e também às médias observadas por Silva et al. (2009) de cultivares na época de safrinha do Sudoeste goiano.

Albuquerque et al. (2011), ao avaliar a produtividade de grãos de cultivares de sorgo granífero em condições semiáridas do Norte de Minas Gerais, observaram produtividades médias de cultivares de sorgo granífero entre 5.500 e $7.000 \mathrm{~kg} \mathrm{ha}^{-1} \mathrm{em} \mathrm{um}$ ano chuvoso e valores inferiores a $3.000 \mathrm{~kg} \mathrm{ha}^{-1} \mathrm{em}$ um ano com baixa disponibilidade pluviométrica. Já Heckeler (2002) observou produtividades de grãos de sorgo granífero entre 4.736 a $9.865 \mathrm{~kg} \mathrm{ha}^{-1}$ em plantio direto no outono-inverno de Dourados, MS. Enquanto que Mariguele \& Silva (2002) observaram produtividades de grãos em torno de $7.960 \mathrm{~kg} \mathrm{ha}^{-1}$, em experimento avaliado em Mossoró sob irrigação plena.

Pelos resultados da seleção de modelos pelo procedimento Stepwise, considerando o rendimento de grãos como variável dependente e as outras variáveis explicativas, observou-se que apenas as variáveis dias para florescimento e índice de trilha foram as variáveis mais importantes, dentre as avaliadas, para se concluir a respeito da produtividade de grãos no ambiente com estresse hídrico. Fixando-se a variação do índice de trilha, foi estimado que, dentro do intervalo de dias para florescimento observado (Figura 3), quanto maior for o número de dias entre a emergência de plântulas e o florescimento, menor será 
a produtividade, em uma razão de $162,28 \mathrm{~kg} \mathrm{ha}^{-1}$ por dia, o que mostra a importância do uso de cultivares precoces em ambientes passíveis de estresse hídrico. Considerando o intervalo observado para o índice de trilha (Figura 4), foi estimado que seu aumento explica o aumento na produtividade de grãos (Tabela 2), ou seja, maior número de grãos, grãos de diâmetro maior ou de maior densidade em relação à panícula influenciam diretamente na produtividade.

No ambiente sem estresse hídrico, as variáveis importantes para explicação do rendimento de grãos foram altura e índice de trilha. O aumento dessas duas variáveis favorece a compreensão a respeito do aumento na produtividade de grãos. A variável dias entre a emergência de plântulas e o florescimento não foi importante nesse ambiente, evidenciando que, nesse ambiente, o efeito do desenvolvimento vegetativo foi mais importante que a quantidade de dias demandada para o desenvolvimento, enquanto que, no ambiente onde foi submetido o estresse, o mais importante é que o desenvolvimento vegetativo seja rápido para que se consiga atingir a fase reprodutiva antes da ocorrência do déficit hídrico.
Considerando os dois ambientes, o aumento das variáveis altura, florescimento e índice de trilha interferiu no aumento da produtividade de grãos, indicando que indivíduos que demandam mais dias para florescer e, consequentemente, possuem um maior desenvolvimento vegetativo, tendem a ser mais produtivos.

No ambiente com estresse hídrico, o procedimento Stepwise selecionou um modelo em que a precocidade explica o aumento na produtividade de grãos, ratificando que a precocidade foi importante apenas em condições de estresse.

Em todos os casos, a variável índice de trilha se mostrou importante para explicar o aumento do rendimento de grãos, indicando que essa característica pode ser considerada no auxílio da seleção, independente do ambiente a ser considerado.

De acordo com Mahalakshmi et al. (1996), a variável índice de colheita foi a melhor alternativa para seleção de genótipos de milheto em condições de estresse hídrico. Magalhães \& Durães (2003) consideram esse caractere um importante discriminador de genótipos de sorgo com eficiente mecanismo de tolerância ao estresse hídrico.

TABELA 2. Resumo dos modelos ajustados pelo procedimento Stepwise considerando a característica produtividade de grãos como variável dependente e as outras características como variáveis explicativas. Nova Porteirinha, MG, 2008.

\begin{tabular}{|c|c|c|c|c|c|c|c|c|c|c|}
\hline \multirow{3}{*}{$\frac{\text { Ambientes }}{\text { Ambos }}$} & \multicolumn{8}{|c|}{ Coeficientes de regressão } & \multirow{3}{*}{$\begin{array}{l}\mathrm{R}^{2^{*}} \\
(\%)\end{array}$} & \multirow{3}{*}{$\begin{array}{c}\text { CV } \\
(\%)\end{array}$} \\
\hline & \multicolumn{2}{|c|}{ Intercepto } & \multicolumn{2}{|c|}{ Altura } & \multicolumn{2}{|c|}{ Florescimento } & \multicolumn{2}{|c|}{ Índice de trilha } & & \\
\hline & $-29763,61$ & $\pm 6090,77^{2}$ & 62,74 & $\pm 13,09$ & 132,34 & $\pm 78,76$ & 248,43 & $\pm 57,86$ & & \\
\hline S. E. ${ }^{1}$ & $-12711,18$ & $\pm 9349,00$ & 32,23 & $\pm 26,85$ & - & - & 200,85 & $\pm 132,73$ & 38,88 & 12,94 \\
\hline C. E. & 6466,92 & $\pm 5551,81$ & - & - & $-162,27$ & $\pm 67,77$ & 109,85 & $\pm 45,35$ & 48,85 & 14,57 \\
\hline
\end{tabular}

"Todos modelos foram significativos $(\mathrm{P}<0,01)$; ${ }^{\mathrm{N}}$ S.E.: sem estresse e C.E: com estresse; ${ }^{2}$ Intervalos de confiança a $95 \%$ de probabilidade obtidos pela distribuição $t$. 


\section{Conclusões}

O estresse hídrico diminuiu a média de todas as características avaliadas, sendo que, em geral, os híbridos responderam de forma semelhante, diante da variação ambiental para a maioria das características.

Os híbridos pré-comerciais 0306037 e 0009035 se destacaram por serem produtivos e precoces. Os híbridos comerciais DKB 599 e 1 G150 também se destacaram por terem apresentado alta produtividade de grãos.

A altura de plantas não foi fator limitante para a grande maioria dos híbridos e a maioria dos híbridos pré-comerciais foram mais precoces que os comerciais nos dois ambientes.

Os híbridos que se desenvolvem mais rápido tendem a ser mais produtivos sob estresse hídrico, enquanto que, na ausência deste estresse, os genótipos que têm desenvolvimento vegetativo mais longo tendem a apresentar maiores produções de grãos e, em todos os casos, os indivíduos que apresentam alto índice de trilha tendem a produzir mais grãos.

\section{Agradecimentos}

Ao Fundo de Desenvolvimento Científico do Banco do Nordeste do Brasil (BNB), pelo apoio financeiro para a execução da pesquisa.

\section{Referências}

AGRITEMPO. Sistema de Monitoramento Agrotecnológico. Disponível em: <http:// www.agritempo.gov.br/agroclima/sumario $>$ Acesso em: 24 mar. 2013.

ALBUQUERQUE, C. J. B.; VON PINHO, R. G.; RODRIGUES, J. A. S., BRANT, R. S.;
MENDES, M. C. Espaçamento e densidade de semeadura para cultivares de sorgo granífero no semiárido. Bragantia, São Paulo, v. 70, p. 278-285, 2011.

\section{ASSOCIAÇÃO PAULISTA DOS PRODUTORES} DE SEMENTES E MUDAS. Evolução da área e produção de sorgo no Brasil. Disponível em: <http://www.apps.agr.br> Acesso em: 13 jan. 2012.

BLUM, A.; SULLIVAN, C. Y. The comparative drought resistance of landraces of sorghum and millet from dry and humid regions. Annals of Botany, Oxford, v. 57, p. 1243$1251,1986$.

CRUZ, C. D. Programa Genes: Biometria. Viçosa: UFV, 2006. 382 p.

FERNANDES, M. B.; AQUINO, B. F.; CASTRO, J. R.; FERNANDES, V. L. B. Adaptabilidade de cultivares de sorgo granífero a solos salinos da microrregião salineira do estado do Rio Grande do Norte. Pesquisa Agropecuária Brasileira, Brasília, DF, v. 27, n. 2, p. 217222, 1992.

HECKLER, J. C. Sorgo e girassol no outonoinverno, em sistema plantio direto, no Mato Grosso do Sul, Brasil. Ciência Rural, Santa Maria, v. 32, n. 3, p. 517-520, 2002.

IBGE. Levantamento sistemático da produção agrícola. Disponível em: <http://www. ibge.gov.br/home/estatistica/indicadores/ agropecuaria/lspa/defaulttab.shtm>. Acesso em: 13 jul. 2011.

LIMA, N. R. C. B. ; SANTOS, P. M. ; MENDONÇA, F. C.; ARAÚJO, L. C. Critical periods of sorghum and palisadegrass in intercropped cultivation for climatic risk zoning. Revista Brasileira de Zootecnia. Viçosa, MG, v. 40, 
p. 1452-1457, 2011.

MAGAlHÃES, P. C.; DURÃES, F. O. M.

Ecofisiologia da Produçãdo de Sorgo. Sete Lagoas: EMBRAPA-CNPMS, 2003. 2 p. (EMBRAPA-CNPMS. Circular técnica, 86).

MAGAlHÃES, P. C.; DURÃES, F. O. M.; RODRIGUES, J. A. S. Fisiologia da Planta de Sorgo. Sete Lagoas: EMBRAPA-CNPMS, 2003. 4 p. (EMBRAPA-CNPMS. Circular técnica, 86).

MAHALAKSHMI, V.; MONYO, E. S.; PAYNE, W.; QUATTARA, S.; BIDINGER, F. R. Breeding pearl millet for drought tolerance. In: International Conference on Genetic Improvement of Sorghum and Pearl Millet, Lubbock, 1996 Proceedings... Lubbock, USAID, INTSORMIL, ICRISAT. p. 443-454. 1997.

MARIGUELE, K. H.; SILVA, P. S. L. Avaliação dos rendimentos de grãos e forragem de cultivares de sorgo granífero. Caatinga, Mossoró, v. 15, n. 1/2, p. 13-18, 2002.

OLIVEIRA, A. B.; GOMES FILHO, E. Germinação e vigor de sementes de sorgo forrageiro sob estresse hídrico e salino. Revista Brasileira de Sementes, Londrina, v. 31, n. 3, p. 48-56, 2009.

PIMENTEL-GOMES, F. Curso de estatística experimental. 15 ed. Piracicaba: FEALQ, 2009. $451 \mathrm{p}$.

REGAZZI, A. J.; SILVA, H. D.; VIANA, J. M. S.; CRUZ, C. D. Análise de experimentos em látice quadrado com enfase em componentes de variância e aplicações no melhoramento genético vegetal. II. Análise Conjunta.
Pesquisa Agropecuária Brasileira, Brasília, DF, v. 34, n. 11, p. 1987-1997, 1999.

SANTOS, F. G. Cultivares de Sorgo. Sete Lagoas: EMBRAPA-CNPMS, 2003. 3 p. (EMBRAPACNPMS. Circular técnica, 77).

SAS INSTITUTE. SAS/STAT® 9.2 User's Guide. Version 9.2, Cary, 2008. 584 p.

SCHUSTER, I.; CRUZ, C. D. Estatística genômica aplicada a populações derivadas de cruzamentos controlados. 2. ed. Viçosa: UFV, 2008. 567 p.

SILVA, A. G.; BARROS, A. S.; Silva, L. H. C. P.; MORAES, E. B.; PIRES, R.; TEIXEIRA, I. R. Avaliação de cultivares de sorgo granífero na safrinha no sudoeste do estado de Goiás. Pesquisa Agropecuária Tropical, Goiânia, v. 39, n. 2, p. 168-174, abr./jun. 2009.

SINGH, B. R.; SINGH, D. P. Agronomic and physiological responses of sorghum, maize and pearl millet to irrigation. Field Crop Research, Amsterdan, v. 42, p. 57-67, 1995.

STONE, L. R.; SCHLEGEL, R. E.; GWIN, R. E.; KHAN, A. H. Response of corn, grain sorghum, and sunflower to irrigation in the High Plains of Kansas. Agriculture Water Management, Amsterdan, v. 30, p. 251-259, 1996.

TORRES, S. B. Qualidade fisiológica de sementes de sorgo através do teste de estresse hídrico. Ciencia Rural, Santa Maria, v. 27, n. 1, p. 31-35, 1997.

TURNER, N. C. Adaptation to water deficits: a changing perpective. Australian Journal of Plant Physiology, Victoria, v. 43, p. 175-190, 1986. 